\title{
Resenha
}

\section{CRISTOVÃO, V. L. L. (Org.). Gêneros (textuais/discursivos): ensino e educação (inicial e continuada) de professores de línguas. Campinas: \\ Mercado de Letras, 2018. 564p.}

\author{
Priscila Azevedo da Fonseca LANFERDINI* \\ Rayane Isadora LENHARO** \\ Maria Izabel Rodrigues TOGNATO***
}

* Doutoranda em Estudos da Linguagem pela Universidade Estadual de Londrina (UEL). Mestre (2012) pelo mesmo Programa. Atualmente é professora de Língua Inglesa da rede básica de ensino em Guarapuava-PR. Contato: planferdini@yahoo.com.br.

** Doutoranda no Programa de Pós-Graduação em Letras da Universidade Federal do Paraná (UFPR). Atualmente professora colaboradora da Universidade Tecnológica Federal do Paraná (UTFPR) câmpus Curitiba. Contato: rayane.lenharo@gmail.com.

*** Doutora em Linguística Aplicada e Estudos da Linguagem (2009) pela PUC/SP (2009). Mestre em Letras Estudos da Linguagem (2002). Pós-Doutora pela UNIGE - Université de Genève - FAPSE. Contato: belinhatog@yahoo.com.br.

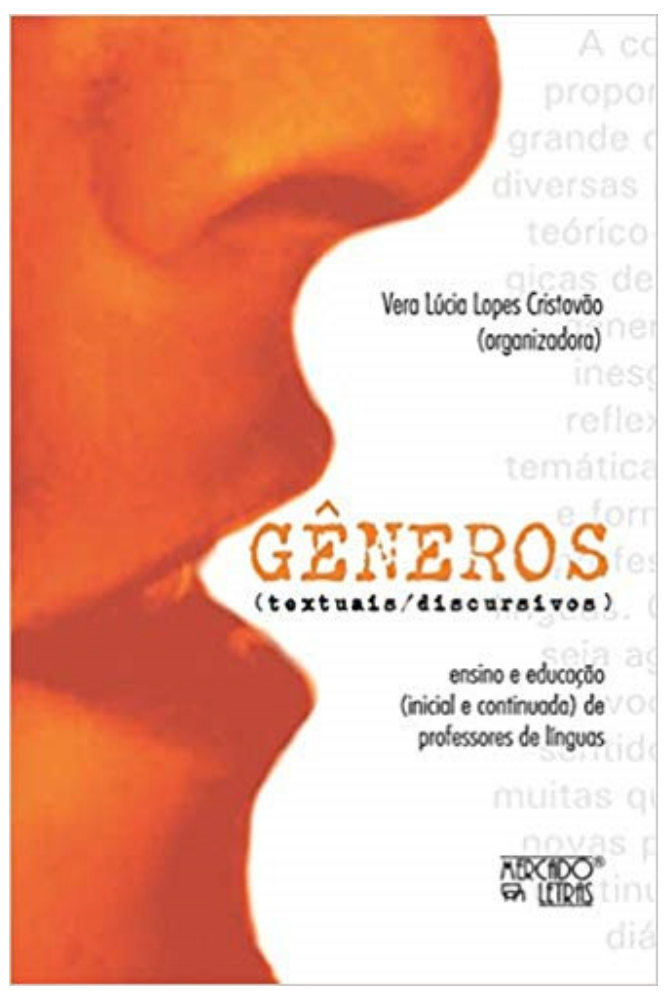

Signum: Estudos da Linguagem, Londrina, v. 21, n. 2, p. 273-279, ago. 2018

Recebido em: 21/06/2018

Aceito em: 08/09/2018 


\section{Resenha ${ }^{1}$}

CRISTOVÃO, V. L. L. (Org.). Gêneros (textuais/ discursivos): ensino e educação (inicial e continuada) de professores de linguas. Campinas: Mercado de Letras, 2018. 564p.

Priscila Azevedo da Fonseca Lanferdini; Rayane Isadora Lenharo; Maria Izabel Rodrigues Tognato

Nas últimas décadas, no Brasil, um número expressivo de pesquisas tem abordado a questão do ensino e aprendizagem de línguas com base em gêneros textuais/discursivos em diferentes perspectivas teóricas. A construção de conhecimentos, a ampliação e a articulação de constructos teóricos possibilitados por tais estudos levou à discussão da existência de uma possível "escola brasileira de gêneros", no VIII SIGET² (BAWARSHI; REIFF, 2010; SWALES, 2012).

Considerando a profusão de teorias sobre gêneros e procurando contribuir com discussões e produção de conhecimento na área, a Profa. Dra. Vera Lúcia Lopes Cristovão tem ofertado, desde 2011, a disciplina Gêneros textuais, Ensino e Educação (Inicial e Continuada) de Professores de Lingua no Programa de Pós-Graduação em Estudos da Linguagem da Universidade Estadual de Londrina (UEL), enfocando reflexões teóricas e metodológicas referentes às diferentes tradições de estudos de gêneros, a saber: Interacionismo Sociodiscursivo (ISD); Nova Retórica; Línguas para Fins Específicos; Linguística SistêmicoFuncional (LSF); Análise Crítica do Discurso (ACD); e Perspectiva Bakhtiniana.

Fruto desse trabalho, o livro Gêneros (Textuais/Discursivos): ensino e educação (inicial e continuada) de professores de linguas reúne artigos de mestrandos e doutorandos que cursaram a disciplina no $1^{\circ}$ semestre de 2013, e de pesquisadores convidados representantes de diferentes perspectivas. O livro é constituído de uma Apresentaşão assinada pela organizadora e 22 capítulos, divididos em três partes que versam sobre: o conceito de gêneros em diferentes tradições de estudo (capítulos 1-9), os gêneros no ensino de línguas (capítulos 10-16) e as contribuições do tema para a formação docente (17-23).

\footnotetext{
${ }^{1}$ Resenha produzida como trabalho de conclusão da disciplina "Gêneros Textuais: Ensino e Educação (inicial e continuada) de professores de línguas", do Programa de Pós-graduação em Estudos da Linguagem (UEL) ministrada pela Profa. Dra. Vera Lúcia Lopes Cristovão, no primeiro semestre de 2015.

${ }^{2}$ O VIII SIGET (Simpósio Internacional de Estudos de Gêneros Textuais) ocorreu de 08 a 10 setembro de 2015 na Universidade de São Paulo (USP).
} 
No primeiro capítulo, Elvira Lopes Nascimento e Adair Vieira Gonçalves explicam que, no Brasil, o ISD teve grande aceitação e reconhecimento, sobretudo em relação à didática de línguas, e que os seus fundamentos centrais voltam-se às questões do desenvolvimento humano. Os autores propõem uma discussão acerca dos seguintes aspectos: a) as contribuições do ISD quanto ao uso de instrumentos semióticos; b) o modelo de análise de textos de Bronckart (2009); c) a problemática da transposição didática. Salientam, ainda, a relevância de questões de letramento e das relações entre linguagem e o trabalho docente.

No capítulo seguinte, Orlando Vian Jr. apresenta diferentes acepções do conceito de gênero por renomados teóricos da LSF, defendendo as articulações entre ela e outras perspectivas. $\mathrm{O}$ autor discute aspectos teóricos e metodológicos do trabalho com gêneros a partir de propostas pedagógicas e de formação docente segundo as diferentes tradições de estudo de gêneros. Por fim, apresenta os procedimentos teórico-metodológicos para a análise de gêneros, relatando iniciativas didáticas da LSF no Brasil e na Austrália.

No Capítulo 3, Eliane Gouvêa Lousada discute sobre o conceito de instrumento proposto por Vygotsky a partir das (re)interpretações de Rabardel (1995), Clot (1999, 2007) e Friedrich (2012) e discorre sobre os fundamentos centrais do ISD e sobre o modelo de análise de texto de Bronckart (2010). Nesse sentido, a autora defende que os gêneros podem ser instrumentos psicológicos para o desenvolvimento das capacidades de linguagem (CL).

No quarto capítulo, Antonia Dilamar Araújo discorre sobre os resultados de um trabalho realizado em uma disciplina de Produção Escrita com estudantes do $6^{\circ}$ semestre de um curso de licenciatura em Letras-Inglês. Os dados analisados incluíram um questionário sobre hábitos de escrita dos alunos e suas produções. Os resultados indicaram que a escrita de gêneros acadêmicos possibilitou o exercício do papel de agentes e a apropriação de conhecimentos específicos da área.

No Capítulo 5, Gladys Quevedo-Camargo, Ana Paula M. Beato-Canato e Lidia Stutz apresentam uma síntese das suas pesquisas de doutoramento e uma reflexão sobre os caminhos por elas percorridos. Ao cruzar os resultados alcançados, as autoras destacam as possibilidades de desenvolvimento das CL e de capacidades docentes dos participantes das pesquisas, bem como a necessidade de um trabalho sistemático para propulsionar desenvolvimento.

No capítulo seguinte, Rodrigo Acosta Pereira e Rosângela Hammes Rodrigues, ancorados nos estudos do Círculo de Bakhtin ${ }^{3}$, discutem questões teórico-metodológicas identificadas em pesquisas de perspectiva dialógica, tomando a interação como princípio fundamental no estudo da linguagem. Os autores concluem que estudos com base no Círculo

\footnotetext{
${ }^{3}$ O Círculo de Bakhtin foi um grupo de pesquisadores russos interessados no estudo da linguagem e do pensamento. Dentre eles, figuram Mikhail Bakhtin, Valentin Volóchinov, Pável Medviédev, dentre outros.
} 
apresentam um percurso teórico-analítico, sem partir de categorias prévias de análise. A busca da interpretação, de regularidades e das singularidades dos dados dá-se no próprio processo de pesquisa.

No sétimo capítulo, Cristina Mott Fernandez e Eliane Segati Rios-Registro discutem os critérios determinados por documentos oficiais do Programa Nacional do Livro Didático (PNLD) referentes à concepção de gêneros de textos para a produção das coleções didáticas de Língua Inglesa (LI). As autoras identificam a concepção de ensino empregada nos documentos a partir do levantamento dos gêneros contemplados em sete coleções aprovadas pelo PNLD/2011. Os resultados indicam que, embora os documentos procurem declarar um entendimento social da língua, primam pela abordagem comunicativa.

No Capítulo 8, Beatriz Gaydeczka apresenta análises de textos de alunos do Ensino Fundamental finalistas da Olimpíada de Língua Portuguesa (OLPEF/2008) e discute como os sentidos são construídos nas produções, partindo dos princípios da concepção bakhtiniana dialógica de linguagem. Os resultados evidenciaram a presença da voz do outro nos enunciados e as coerções sociais que permeiam todo projeto enunciativo.

Nesta primeira parte do livro destaca-se a apresentação de diferentes escolas de gêneros de texto, o que enriquece o contato do leitor com perspectivas distintas com foco em temas semelhantes. Caracteriza-se como a parte teoricamente mais rica e densa, uma vez que introduz conceitos que podem não ser tão familiares aos leitores.

Abrindo a segunda parte do livro, Lilia Santos Abreu-Tardelli, Fernando Silvério de Lima, Rita Rodrigues de Souza, Neuraci Rocha Vidal Amorim e Juliane Ferreira Marques de Freitas sintetizam conceitos da abordagem teórica do ISD ao destacar estudos que defendem gêneros como instrumentos de desenvolvimento. $\mathrm{O}$ trabalho foi motivado pela divulgação de textos críticos ao ISD que, segundo os autores, parecem não conhecer a fundo a proposta didática mencionada, e de outros que dizem fundamentar-se no ISD, mas que apresentam uma visão reducionista da perspectiva. Em resposta a tais publicações, os autores sintetizam e articulam conceitos do ISD, propondo uma reformulação do esquema de Sequência Didática (SD) (DOLZ; SCHNEUWLY, 2004).

No décimo capítulo, Claudia de Faria Barbeta e Ednéia Ap. Bernardineli Bernini analisam atividades desenvolvidas em torno de gêneros digitais, encontradas em dois volumes de livros didáticos de Língua Portuguesa, utilizados em escolas públicas no estado do Paraná, a fim de observar se elas compreendem o gênero enquanto prática de ação social. Os resultados revelam que os livros didáticos analisados procuram contemplar timidamente gêneros digitais.

No Capítulo 11, Juliane D’Almas discute cognições ${ }^{4}$ de alunos-professores de um curso de Letras-Inglês sobre a proposta de ensino de Línguas Estrangeiras por meio de

\footnotetext{
${ }^{4}$ Com base em Borg (2003), D’Almas explica que as cognições estão relacionadas ao pensamento dos professores, ou seja, àquilo que os professores pensam, sabem e acreditam.
} 
gêneros textuais. Os dados foram gerados a partir de entrevistas com grupo focal. Os resultados revelam que os alunos-professores compreendem o ensino por meio de gêneros como um instrumento de ensino-aprendizagem, todavia apresentam cognições abrangentes sobre a abordagem e dificuldades em compreender como usá-la em sala de aula.

No Capítulo 12, Daiane Eloísa dos Santos e Luiz Antonio Xavier Dias investigaram os níveis de responsividade em um fórum de discussão online promovido pela plataforma Moodle. Os autores ancoraram-se nos pressupostos do Círculo de Bakhtin e no entendimento da Linguística Aplicada enquanto área indisciplinar (MOITA LOPES, 2006). As análises mostraram que esse espaço proporcionou engajamento dos participantes nas atividades, uma vez que apenas $5 \%$ do total de respostas se configuraram como participações de forma silenciosa ou sem criticidade.

O Capítulo 13 trata da interação em ambiente virtual e do desenvolvimento de CL em Língua Espanhola. Na pesquisa, Amábile Piacentine Drogui utiliza a plataforma Moodle e o fórum de discussão como fontes de dados para a investigação. O diferencial do estudo é a participação tanto de professores brasileiros quanto argentinos, o que promoveu uma troca de cunho educacional e cultural.

O décimo quarto capítulo apresenta análises de uma unidade didática da coleção de livros didáticos de LI Upgrade. Para tanto, Claudinei Aparecido Canazart e Fernanda de Cássia Miranda partem dos pressupostos das Diretrizes Curriculares Estaduais do Paraná para Língua Estrangeira. Os autores avaliaram as atividades presentes na unidade e concluíram que o ensino de aspectos gramaticais da língua é privilegiado em detrimento a outros, além de que a habilidade de leitura predomina.

Fábio Henrique Rosa Senefonte e William F. Rabelo da Silva realizaram uma pesquisa bibliográfica sobre o ensino de Língua Portuguesa como Língua Estrangeira com base na abordagem de gêneros. Para tanto, os autores evidenciaram diferenças entre cinco escolas de gêneros e, posteriormente, expuseram dados da recensão bibliográfica realizada. Os resultados indicaram uma escassez de trabalhos na temática pesquisada.

A segunda parte do livro, assim como a primeira, apresenta riqueza em diversidade de trabalhos com gêneros de texto em diferentes contextos de atuação, com destaque para gêneros da esfera digital e uso de plataformas online como o Moodle. Corroboramos, assim, o conteúdo apresentado, pela sua relevância na área de Linguística Aplicada.

Iniciando a terceira parte do livro, Ana Claudia Cury Calia de Souza e Vera Lúcia Lopes Cristovão discutem sobre a percepção que professores têm de si mesmos em relação à utilização de livros didáticos em sala de aula de LI. Baseadas nos pressupostos do ISD, as autoras apresentam análises de transcrições de uma oficina voltada à análise de materiais didáticos e sua consonância com as prescrições do PNLD. O estudo envolveu professores da rede estadual de ensino do Paraná, um autor de livro didático e assistentes editoriais. Os resultados apontaram para uma posição passiva do professor no processo de avaliação e seleção dos livros. 
No Capítulo 17, Ana Valéria Bisetto Bork e Francine Percinoto Poliseli Corrêa analisaram os Projetos Político Pedagógicos (PPC) de dois cursos de licenciatura em Letras, a fim de investigar se os documentos contemplam o ensino por meio de gêneros. As autoras constatam que em uma instituição houve forte influência da perspectiva de gêneros com base no ISD, enquanto na outra observou-se predominância da perspectiva vigotskiana.

No Capítulo 18, Alessandra Augusta Pereira da Silva analisa trocas verbais produzidas por professores formadores em reuniões para produção de planos de ensino em um curso de Letras. A autora discute os principais temas evocados pelos participantes durante uma das reuniões, com relação à temática dos gêneros e seu uso para o ensino de LI. Os resultados apontaram que, embora no discurso dos professores houvesse argumentos tanto a favor quanto contra o trabalho com gêneros, de forma geral, os docentes careciam de informações teórico-metodológicas sobre esse conceito.

O trabalho de Jozélia Jane Corrente Tanaca e Alexandre Stein aborda as temáticas políticas e didáticas envolvendo o ensino de LI para crianças. Os dados são provenientes de respostas a questionários de três professoras em formação continuada. Entre os resultados, destaca-se a carência de informações metodológicas, por parte das professoras, sobre o ensino com base em gêneros.

No vigésimo capítulo, Claudia Lopes Pontara apresenta análises de três versões de uma SD produzida para o contexto do Centro de Línguas Estrangeiras Modernas (CELEM), enfocando suas organizações internas e externas. A pesquisadora conclui que, quando os professores dispõem de tempo para reflexão e sistematização dos conhecimentos adquiridos em sua formação, há maior aproveitamento e desenvolvimento do trabalho em relação à produção e à implementação de SD.

No último capítulo, Letícia Aparecida de Araújo Gonçalves e Loretta Derbli Durães da Luz Rosolem contribuem com um modelo didático do gênero infográfico. Embasadas no ISD, as autoras traçam as principais características do gênero a partir da análise de cinco exemplares publicados na revista Superinteressante. As pesquisadoras destacam que o infográfico é um texto multimodal, contendo imagens, formas e cores diversas que contribuem para a compreensão de sentido.

De forma geral, esta obra oferece importantes contribuições para a área de estudos de gêneros, uma vez que possibilita o cotejamento de conceitos teóricos e procedimentos metodológicos de diferentes perspectivas; além disso, abrange a relação entre os gêneros e uma série de outras questões que permeiam o ensino de línguas. A diversidade temática e a organização da coletânea oferecem subsídios que podem contribuir para o entendimento dos referenciais teóricos apresentados e para a sua utilização em diferentes contextos.

Enfim, o diálogo proporcionado entre as perspectivas teóricas torna esta obra inédita e de leitura essencial a todos aqueles (professores e/ou pesquisadores) interessados em ampliar seu olhar para além de sua filiação teórica e/ou realizar articulações entre as diferentes tradições de estudos de gêneros. 


\section{REFERÊNCIAS}

BAWARSHI, A. S.; REIFF, M. J. Genre: an introduction to history, theory, research, and pedagogy. West Lafayette, IN: Parlor Press; The WAC Clearinghouse, 2010.

BORG, S. Teacher cognition in language teaching: a review of research on what language teachers think, know, believe and do. Language Teaching, Cambridge University Press, v. 36, p. 81-109, 2003.

BRONCKART, J. P. Atividade de linguagem, textos e discursos: por um interacionismo sóciodiscursivo. Tradução de Anna Rachel Machado e Péricles Cunha. São Paulo: EDUC, 2009 [1997].

BRONCKART, J. P. Gêneros de textos, tipos de discurso e sequências. Por uma renovação do ensino da produção escrita. Letras, Santa Maria, v. 20, n. 40, p. 163-176, jan./jun. 2010.

CLOT, Y. La fonction psychologique du travail. Paris: PUF, 1999.

DOLZ, J.; SCHNEUWLY, B. Gêneros e progressão em expressão oral e escrita elementos para reflexões sobre uma experiência suíça (francófona). In: SCHNEUWLY, B.; DOLZ, J. et al. Gêneros orais e escritos na escola. 2. ed. Tradução Roxane Rojo e Glaís Sales Cordeiro. Campinas: Mercado de Letras, 2004.

FRIEDRICH, J. Lev Vigotski: mediação, aprendizagem e desenvolvimento. Campinas: Mercado de Letras, 2012.

MOITA LOPES, L. P. Por uma lingüística indisciplinar. São Paulo: Parábola, 2006.

RABARDEL, P. Les hommes et les technologies. Paris: Armand Colin, 1995.

SWALES, J. M. A text and its commentaries: toward a reception history of "Genre in three traditions" (Hyon, 1996). Ibérica, n. 24, p. 103-116, 2012. 